\title{
Video-Mediated Approaches for Community-Level Climate Adaptation
}

\author{
Pablo Suarez, Fiona Ching, Gina Ziervogel, Isabelle Lemaire, \\ Diane Turnquest, Janot Mendler de Suarez and Ben Wisner*
}

\begin{abstract}
1 Introduction
It is generally recognised that the poorest sectors of the global population tend to be most sensitive to climate variability and change (UNDP 2003).

Numerous pro-poor adaptation initiatives are under way at multiple levels, yet the prevailing discourse and practice linking vulnerability and adaptation is commonly plagued with generalisations, offering limited examination of the dynamic and differentiated nature of poverty (Tanner and Mitchell, this IDS Bulletin, 'Entrenchment or Enhancement').

Inequities in the patterns of flow and use of information remain a fundamental challenge of modern times (Lievrouw and Farb 2003). This is particularly relevant in the realm of communitybased disaster risk management. The poor often face severe constraints that impede proper use of available information about climate-related risks (Patt and Gwata 2002), and there is evidence that participatory approaches to community-level risk management can significantly improve the benefits of using climate information (Patt et al. 2005). Most success stories are derived from pilot projects, and the imperative is now to accelerate the process of replication and dissemination of best practices.
\end{abstract}

A major challenge for the Red Cross/Red Crescent movement and other humanitarian organisations is how to scale-up successful adaptation pilots. Clearly it is not feasible to dispatch technical experts to every location with poor people threatened by climate risks. It is necessary to ensure that a wider range of users can access and utilise the information available for climate risk management (Ziervogel and Downing 2004), yet evidence from the fields of development and poverty reduction suggests that a 'one size fits all' approach is unlikely to work, given the complexity of factors that can cause and entrench poverty (Klein et al. 2007; Mitchell and Tanner 2006).

Community-level adaptation initiatives need to provide information and knowledge in a form that is accessible and useful to local decision-makers. This requires treating the end-users of information not merely as a target audience but as partners in co-learning. Thus, care must be taken so that processes and products reflect their own contributions (Roncoli 2006). Propoor adaptation needs to overcome the onedimensional view of poverty that prevails in much climate change work, drawing from development studies in understanding categories of poverty (such as the 'chronic poor', 'transient poor' and 'never poor' types presented by Jalan and Ravallion 2000), and tackling the specific challenges and opportunities presented by climate change in a way that adequately addresses the complexity of local poverty.

Audiovisual technologies are increasingly affordable for capturing, processing, storing and disseminating information. Videos and other communication tools, if combined with participatory approaches, may help extend the benefits of available information to all those who could take advantage of it, in a way that is sufficiently tailored to local needs and constraints (Figure 1). While other disciplines, such as the health sciences, have been dedicating considerable efforts to developing and evaluating intervention strategies that involve the use of video tools, adaptation research and practice has yet to take audiovisual tools into serious consideration.

The making of and discussion about a video can provide an ideal mediation space to bring together the 
Figure 1 Elements of the proposed video-mediated approach

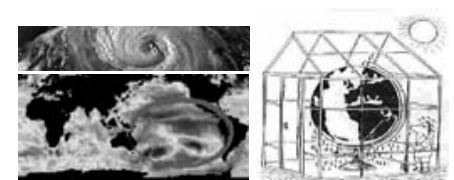

Climate risk information

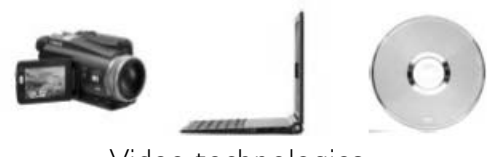

Video technologies



Participatory, community-based adaptation to climate variability and change

multiple stakeholders needed to address climate change in a way that emphasises the differentiated nature of poverty for the policy and practice of adaptation. Participatory video is a particularly relevant methodology, which aims at involving a group or community in shaping, creating and filming their own film, from storyboarding to interviewing and camera operation (Pink 2004; Lunch and Lunch 2006). Participatory video establishes trust and treats local knowledge with respect, and is increasingly used in community development and anthropological research. It has the potential to create spaces for transformation by providing a practice of looking 'alongside' rather than 'at' research subjects (Kindon 2003). This is fully aligned with the growing recognition among disaster risk reduction scholars and practitioners that end-users of information need to be co-producers of new knowledge (Wisner et al. 2004).

This article makes a case for more comprehensive development, use and evaluation of audiovisual tools in order to scale-up climate adaptation in a pro-poor way. The next section offers an overview of the experiences from the health sector in the use of audiovisual media. Case studies from Argentina, the Bahamas, Indonesia and Malawi led by the Red Cross are then described, followed by an outline of the possible uses of video-mediated approaches for climate risk management. The final section sets out conclusions and recommendations.

\section{Use of audiovisual tools for risk management: Lessons from the health sector}

There is an abundant body of literature exploring, reporting and rigorously analysing the use of video tools for health risk management. A clear example is work commissioned by the Health Education Authority of the UK, which systematically reviewed 175 studies of video-based projects with the aim of assessing the value of video as a tool for health promotion and education (Eiser and Eiser 1996). The report, which gives examples of well-planned and well-evaluated projects, concludes that audiovisual tools can produce changes in attitudes and knowledge, and outlines the key elements for successful initiatives.

Many articles in peer-reviewed journals offer statistically rigorous analysis of the value of video interventions among poor communities that are particularly at risk (for a detailed review of this literature, see Suarez and Mendler de Suarez 2006). For example, Rimm (2003) describes the process involved in making an educational video to inform rural communities in Tanzania about the health risks and prevention of porcine cysticercosis (a parasitic disease). The article highlights the importance of developing strategies for production and use of the film as extension material.

Martin et al. (2005) report on an educational video for tuberculosis awareness in the Gambia using participatory methods and integrated formative evaluation. Audiences were able to identify the key messages; their prevailing attitudes about tuberculosis were challenged, and many participants expressed a desire to act on their new knowledge. Mitchell et al. (2001) evaluate four channels used in a community-based HIV/AIDS intervention in rural Uganda (drama, video, community educators and leaflets). Over 85 per cent of the community rated 
the video as relevant and realistic. However, since the messages 'taken home' were not always those intended by the project team, the authors suggest that a multi-channel approach may be required to overcome weaknesses inherent in single channels.

In addition to community-based approaches to using video, much can be learned from the health field in terms of broader approaches to risk management and capacity building. For example Whitehead (2000) discusses the enormous potential for mass media resources to reach certain audiences and influence their health-related behaviours. DeJong (2002) describes key principles of health-related media campaigns, including the integration of information and advocacy approaches to create a climate of support for institutional, community and policy changes aimed at altering the environment in which people make decisions.

Gray (1996) describes the making and testing of a 40minute video to educate staff about a hospital disaster plan. A multiple-choice questionnaire was used to compare information recall in a group who had seen the video and a group who had read the written plan. The video group scored significantly higher than the reading group $(p<0.01)$, with mean scores of 72 per cent and 45 per cent, respectively. Videos improved recall of emergency procedures proving to have an impact that was absent in written disaster plans.

Given the similarities of how information format and content can shape decision-making, it is reasonable to assume that the findings from the health sector are applicable to climate risk management.

\section{Red Cross case studies: Malawi, the Bahamas,} Argentina and Indonesia

The Red Cross/Red Crescent Climate Centre, which supports the Red Cross and Red Crescent Movement and its partners in reducing the impacts of climate change and extreme weather events on vulnerable people, has been developing video tools since 2005 to support awareness, action, advocacy and analysis. The first pilots were developed informally with volunteer film-makers in Argentina, Bangladesh and Mozambique, and by 2008 there had been activities with over a dozen national societies.

The rationale for investing in video was built on the awareness that community adaptation is essentially about change in human behaviour, and such change is more likely to happen when people find both intellectual and emotional reasons to think and act differently. Audiovisual tools can help to communicate scientifically complex issues in simple ways, with reliable accuracy, and using aesthetic approaches that can inspire and motivate, sometimes in surprising ways.

For example, after a workshop on flooding with Mozambiquan farmers, participants watched a fourminute video from a similar workshop held in a floodprone Argentinean shantytown. After seeing the short film on a laptop screen, one of the female farmers said to the workshop facilitator: 'I had followed your explanations of global warming, but didn't fully believe you ... We've had the 2000 floods that killed so many people and since then two dry spells, and like everybody else I thought it was God punishing us, or that the ancestors were angry ... and we can't do much about it. But now in the film I see that white women at the other end of the world have the same problem we have! So maybe it is true that the global rainfall is changing, and if so I can do something about it. I will.' The video had touched this farmer in a way that motivated her to consider changing crops to adapt to different climatic conditions.

Video-mediated approaches can be designed to tackle the poverty-related aspects of adaptation in the humanitarian work of the Red Cross. For example, following Jalan and Ravallion (2000), the chronic poor may benefit from video tools that promote the building of pathways out of poverty given availability of new funding for adaptation (e.g. through changing agricultural production systems or improved provision of public services by the state), whereas the transient poor may benefit from audiovisual products that help people at risk deal with the climate-related shocks that occasionally pull them below the poverty line (through improved early warning systems and eventspecific risk reduction measures). Similarly, it is fundamental to address the heterogeneity of vulnerabilities and capacities inherent at the community level - and too often overlooked (van Aalst et al. 2008). For example, gender dimensions play a crucial role in local adaptation (Patt et al. 2008 in press). Participatory video tools have proved useful for giving a voice to the marginalised members of a community (such as women and children), helping the Red Cross fulfill its humanitarian mandate.

The following case studies illustrate the video-mediated approach to adaptation in four very different contexts. 


\subsection{Video tools by and for subsistence farmers in Malawi}

With a life expectancy of 41 years, high levels of illiteracy and a population very dependent on rainfed agriculture, Malawi is extremely vulnerable to climate change (Environmental Affairs Department 2006). The Malawi Red Cross and Malawi Meteorological Services have been collaborating in a project entitled 'Audiovisual tools for community-based adaptation', as part of the ACCCA (Advancing Capacity for Climate Change Adaptation) programme. The project aims to strengthen capacity for adaptation among subsistence farmers through improved communication and use of climate predictions.

The location chosen for this project, Mphunga Village (Ndindi, Salima district), is subject to frequent droughts and floods. After a process of sharing information between climate experts and the community members, participatory video methods were used to invite farmers to develop their stories around the impacts and response to flooding. Participants started working with photo cameras to think about what story they wanted to tell. The photographs were then used to develop storyboards for the video. The participants learned to use film-making equipment and captured the impacts and responses to flooding. $A$ film-maker edited the footage into a 20-minute piece, with English subtitles.

This initial video gives a good overview of how people in Mphunga village are impacted by floods. It also shows the measures already implemented to reduce flood impacts, including relocation of the school, building houses from reeds that can be moved quickly during floods, and planting reeds on the river bank in order to reduce siltation and water damage - mostly measures that would reduce the impact of shocks that currently contribute to farmer's inability to escape poverty. Projecting this video to village members helped generate discussion on what was learned from the process, what new issues had emerged since filming, and how additional video products could share the message of potential adaptation strategies with other people at risk.

Remaining project tasks include (1) expanding the video products made by and for the more marginalised people within the community (including female farmers and children); (2) developing new video tools aimed at training Red Cross staff and volunteers about how to communicate and use information for climate risk management; and (3) equipping the Malawi Red Cross with mobile video projection units to show the videos as part of participatory processes in remote communities.

\subsection{TV spot for hurricane preparedness in the Bahamas}

The Bahamas is a country exposed to increasingly intense hurricanes, and its economy is highly dependent on the tourism sector, which in turn depends on fragile natural systems threatened by global warming. The poorest people in this small island state, affected by seasonal and overall unemployment or declining productivity of coral reefs, are not well prepared for managing climaterelated risks.

With funding from the European Commission, the Bahamas Red Cross developed a set of short videos during 2006 to promote community-level hurricane preparedness. Importantly, the very making of these videos created a remarkable spirit of collaboration between the Red Cross and numerous other institutions involved in disaster risk management, from the technical experts to the media. The director of the National Emergency Management Agency (NEMA), after joining a workshop on participatory video and climate change organised by the Red Cross, called for a high-level government meeting attended by about 30 people to discuss adaptation needs and support the Red Cross video work.

Building on local voices and a dynamic aesthetic approach, the audiences of the resulting videos are first exposed to information about how the climate is changing and what that means for the island, including the risk of stronger hurricanes. Then they learn about how the Red Cross is working with others, strengthening its capacity to help Bahamians respond to disasters faster. The key message of the video is 'the climate is changing, and so are we'.

As a result of this first video project, several new initiatives emerged. A partnership between NEMA, the Red Cross, the main TV station and others resulted in the first climate change video competition in the country. All participants had to learn about climate risks, helping raise awareness and give visibility to the Red Cross efforts. The winning entry, entitled Three Bahamians in a Bathtub, has been aired repeatedly during hurricane season together with the short videos. Today the Bahamas 
Red Cross and NEMA have a core team of instructors who travel together to the different islands to lead workshops on disaster preparedness and risk reduction among the poor.

\subsection{Video as enabler of policy-level dialogue to address Argentina's urban risks}

Argentina is a relatively wealthy and highly urbanised country by Latin American standards, but its populous shantytowns generally lack basic services, such as water, sanitation and waste management, and tend to occupy land prone to frequent flooding that will likely become more severe with climate change.

Between March and December 2006, the Argentinean Red Cross collaborated with local filmmakers in the context of a project entitled 'Use of video tools for disaster management and climate adaptation', supported by the Potsdam Institute for Climate Impact Research (PIK). The Red Cross team indicated at the outset that it wanted a video tool for motivating urban communities at risk to engage in Vulnerability and Capacity Assessments (processes aimed at understanding and transforming reality so that hazards do not become disasters).

A workshop on climate change was held in Monte Matadero, a shantytown on the south-eastern edge of the Buenos Aires metropolitan area. While some of the proposed adaptation ideas that emerged could be implemented with resources available among the urban poor, the most important ones depended on the engagement of other institutions (e.g. early warnings, provision of sanitation services and construction of a community evacuation centre) It became evident to the Argentinean Red Cross that engaging vulnerable people in climate change adaptation would not be as challenging as engaging other institutions which need to play a vital role in supporting community adaptation initiatives. Two months before the end of the project, it was decided to reformulate the objectives: the proposed product would be aimed at high-level decisionmakers in government, academia, the private sector, donors and other non-governmental organisations (NGOs) to invite them to work with the Red Cross in supporting adaptation processes, under the leadership of the community itself.

A pilot video was produced with available footage, and projected in December 2006 at a meeting held at the Red Cross headquarters that convened high- level officials (including two members of congress), researchers, the private sector, Red Cross staff and volunteers and three women from the shantytown. Participants identified potential collaboration for adaptation, and provided feedback on the first cut of the video tool. The shantytown residents understood that the Red Cross has the institutional capacity to reach high levels of government and help communicate the demands of the poor, while the more powerful decision-makers witnessed the trust that vulnerable communities have in the Red Cross.

Today the Argentinean Red Cross has fully embraced climate change in its communication strategy. It has established a partnership with the national government agency in charge of climate change adaptation, and is developing more audiovisual tools for awareness raising and mobilisation of resources to support pro-poor adaptation.

\subsection{Participatory video for climate adaptation in a shantytown in Jakarta}

Jakarta experiences intense rainfall year after year, but recently it has seen unprecedented flooding patterns. Jakarta's poorest people live in areas prone to inundation resulting from tidal waves and riverine flooding. Recognising the growing threat, the Indonesian Red Cross launched a two-year programme on integrated community-based risk reduction and climate change.

The idea of integrating participatory video to this programme was proposed by the Climate Centre, welcomed by the project team, and funded by the International Federation of Red Cross and Red Crescent Societies (IFRC). A film-maker with experience in climate issues coordinated the video work in two shantytowns along the main river. Selfselected Red Cross staff and volunteers joined, contributing strong facilitation skills and a keen interest and respect for the community. The participatory video work with villagers lasted 2.5 days in each community. While the original idea was to focus this video on climate change, the project team chose to let the locals develop a sense of total ownership over the film-making process, which resulted in a broader set of issues covered but also a much better connection between the project and the community. An editing company was hired to produce the final cut, and the community was invited to the editing room to approve the final version of the video. A screening was organised in the 
community, followed by an open discussion on the issues addressed in the video, including flooding, waste management, violence and health.

A short documentary was produced separately to specifically address climate change, with expert interviews and professional camera handling. The documentary and participatory video were later brought together in the final product as a hybrid film, combining the local 'rough and ready' and the more 'polished' professional video style. The two worked well together and the resulting video successfully communicates the messages that the Indonesian Red Cross wanted to convey to people's hearts and minds.

\subsection{Common challenges and lessons learned}

It is worth noting some issues common to all case studies. First and foremost, each local Red Cross had very limited knowledge of climate change, almost no experience of making videos with communities, and the usual intensity of competing projects and unpredictable crises to deal with. Outside expertise in film-making or in climate issues was available but limited, and this led to surmountable but difficult problems, such as an initial lack of focus about goals and how to achieve them; long periods of inactivity when a key person was not available; or insufficient follow-up once a product was ready. Additionally, there can be enormous communication challenges when bringing together climate experts, film-makers, humanitarian workers and very poor people at risk for collective work. All of these key players are needed to make an effective video for adaptation, but each brings exceedingly diverse languages, perspectives and priorities, not always easy to harmonise.

A key lesson learned is that the anticipated visibility of the final product brought together many stakeholders in an atmosphere of collaboration and innovation. The video tool, even when it is merely at its conceptual stage, can provide an unusually fruitful space for the Red Cross and other humanitarian organisations to mediate between poor communities at risk and the institutions that can support community-level adaptation to climate change.

\section{Application of video-mediated approaches for} community-level adaptation

Current practice seldom reflects a happy marriage between disaster management and community planning, and this is one of the reasons why local decision-making processes are often devoid of hazard awareness (Pearce 2003) or climate adaptation considerations (Thomalla et al. 2006; O’Brien et al. 2006). Based on the previous sections, we envision four areas as promising dimensions of video interventions for pro-poor adaptation: awareness raising, training, advocacy and community planning

\subsection{Awareness raising}

The potential for audiovisual media to increase awareness is immense. Options include mass media products for broad TV audiences, targeted video projections for policymakers, community groups, educators and others, or mobile projection equipment to reach dispersed rural communities in developing countries.

Video-mediated approaches can be much more successful than oral or written channels to communicate in a simple and convincing manner the complicated scientific knowledge and practical measures that can nurture adaptation, particularly for empowering illiterate people.

\subsection{Training}

Addressing the challenge of adaptation given the diversity of poverty demands sufficient numbers of qualified personnel such as workshop facilitators and community disaster managers, particularly among organisations like the Red Cross which depend on networks of community volunteers.

Training efforts mediated by information and communication technology can help to deepen learning outcomes, especially when utilised in combination with hands-on training sessions (Mendler et al. 2002). Audiovisual tools for training of trainers have been developed and deployed in the water and sanitation sector by meta-networking organisations, such as Cap-Net and the Gender and Water Alliance. Similar tools could be adapted from live training presentations, duplicated on CD or DVD, or even made available via the internet for wide dissemination in the context of broader capacity-building programmes.

\subsection{Advocacy}

Many of the bottlenecks faced by disaster risk management could be more appropriately addressed with better access to human and financial resources. Advocacy tools such as TV campaigns can help mobilise these resources. Additionally, the process of making videos can help form partnerships with entities that have a lot to contribute to climate adaptation. 
A shared vision can be fostered by building consensus horizontally within communities as well as vertically across agencies and institutions with respect to the scientific basis of climate change, its expected impacts, and possible adaptation options to be included in the video tools. One should not underestimate the difficulty and importance of building trust as a precondition of such horizontal and vertical communication, but it is well worth attempting (Lahsen 2007; Wisner and Uitto 2008). Additionally, integrating participatory video methods in the making of such products can enable marginalised groups to articulate their needs and demands - and communicate them effectively to government and other stakeholders.

\subsection{Community planning}

Audiovisual tools can support participatory processes aimed at reducing communities' vulnerability, and help to generate support for local-level climate risk management initiatives. For community action planning purposes, these tools are best used as part of a suite of other methods that have become standard parts of community-based disaster risk reduction, such as season calendars, transect walks, and focus group discussions (Haghebaert et al. 2008).

Videos showing how a variety of strategies can address relevant threats can be an effective means of transferring good practices and lessons learned. Video-mediated interventions can help to inform and trigger adaptation strategies at the community level, supported by the wider governmental, civil society and other key entities.

\section{Conclusion}

The magnitude of the challenges associated with community-level adaptation requires innovative approaches that take into consideration the complexities of poverty and vulnerability. The field of climate adaptation has a lot to learn from other disciplines in the use of audiovisual tools for promoting informed decision-making and convergence of actors. In light of increasing affordability and 'user-friendliness' of the technologies for collecting, processing, storing and disseminating audiovisual material, these tools deserve much more attention among adaptation practitioners.

This article has discussed some of the opportunities offered by video-mediated approaches to climate

\section{Figure 2 Key members of collaborative teams for video-mediated adaptation}

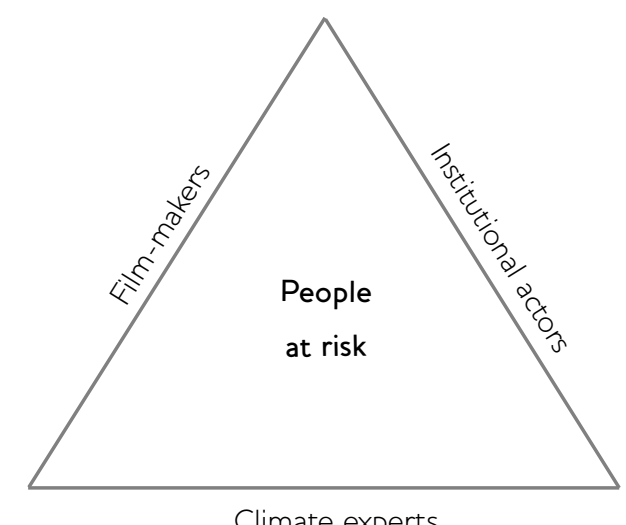

Climate experts

change adaptation, inspired by experiences in health risk management and illustrated by four Red Cross case studies on climate change.

We identify three important areas in which disaster management and climate adaptation practitioners need to invest in order to take full advantage of the potential offered by audiovisual tools:

\section{(i) Developing guidelines for design and} implementation: The production and use of video tools requires communication approaches different from the technically rigorous presentation style that dominates the literature and conferences where disciplinary knowledge is usually shared. It would be desirable to elaborate climate communication methods for the production and use of video tools specifically tailored for participatory approaches to adaptation.

(ii) Developing rigorous assessment methods: Other disciplines, from health sciences to marketing, have well-established methodologies to rigorously assess the effectiveness of video-mediated interventions. It is important to formulate methods and indicators for testing whether video tools are effective for climate adaptation and, if so, to help improve and scale up successful pilots. Such methods could range from rapid assessment tools for course correction during video production stages and fieldwork, to rigorous survey and statistical tools capable of producing 
journal-quality data for evaluation of videomediated initiatives.

(iii) Developing multidisciplinary teams: While researchers and practitioners involved in climate change initiatives have long embraced the idea of cooperation with other scientific fields, little has been done to establish collaboration teams involving climate adaptation experts, film-makers, vulnerable communities, and humanitarian or developmental organisations working with the poor in the field. The literature from other disciplines and Red Cross experience suggest that the video production process needs to be iterative and deeply collaborative, with constant feedback

\section{Note}

* This work was supported by the Potsdam Institute for Climate Impact Research (PIK) - Social Systems Department. The video projects discussed here were funded by PIK (Argentina), DIPECHO (the Bahamas), ACCCA (Malawi) and the IFRC (Indonesia). We acknowledge the generous filmmaking contributions of Andrea Santoro, Ben Pritchett, Bruce Boyd, Conwell Naweya, Dee Portnoy, Fabio Benavídez, Fernanda Baumhardt, Isabelle Lemaire, Justin Benn, Marie-Ange Sylvain, Nadia von Christierson and Simon Taylor. Our deepest gratitude goes to the people of El Zanjón and Monte Matadero (Argentina), Adelaide (the Bahamas), Nali (Bangladesh), Adi Ha (Ethiopia), Kedaung Kali (Indonesia), Ndindi (Malawi), Xai-Xai and Chiguidela (Mozambique), where making and

\section{References}

DeJong, W. (2002) 'The Role of Mass Media Campaigns in Reducing High-risk Drinking Among College Students', Journal of Studies on Alcohol Suppl. 14: 182-92

Eiser, J.R. and Eiser, C. (1996) Effectiveness of Video for Health Education: A Review, Exeter: Health Education Authority

Environmental Affairs Department (2006) Malawi's National Adaptation Programme of Action (NAPA) Lilongwe: Environmental Affairs Department

Gray, D. (1996) 'Disaster Plan Education: How we Made and Tested a Video', Journal of Accident and Emergency Medicine 13.1: 21-2

Haghebaert, B.; Wisner, B. and Schaerer, M. (2008) ProVention Consortium CRA Tool Kit, and involvement from the affected stakeholders into the creative process, and maintenance of a central decision-making role for people at risk.

Team dynamics and complementarities need time to mature into a shared understanding (Figure 2).

Communication strategies are essential for any attempt to bring the advantages of science and technology to decision-makers and stakeholders, particularly given the complex, place-specific nature of poverty and vulnerability. By beginning to chart the interface between audiovisual media and propoor adaptation, we hope that these ideas can assist those seeking to accelerate climate risk management and poverty reduction.

sharing videos for community-level adaptation proved both inspiring and joyful. We are particularly grateful to Richard Klein, whose vision and support set the foundations for our audiovisual work; to Saleemul Huq, who has consistently provided venues to project the videos of the Red Cross/Red Crescent Climate Centre; and to the Climate Systems Analysis Group at the University of Cape Town and the International Research Institute for Climate and Society (IRI) for technical support. This work benefited greatly from conversations with Jamil Simon, Joseph Chalamba, Maarten van Aalst, Madeleen Helmer, Molly Hellmuth, Nick Lunch, Sanjeev Chatterjee, Xavier Castellanos and the Red Cross teams in Argentina, the Bahamas, Indonesia and Malawi. Usual disclaimers apply.

www. proventionconsortium. org/?pageid=39 (accessed 9 July 2008)

Jalan, J. and Ravallion, M. (2000) 'Is Transient Poverty Different? Evidence for Rural China', Journal of Development Studies 36.6: 82-99

Kindon, S. (2003) 'Participatory Video in Geographic Research: A Feminist Practice of Looking?', Area 35.2: $142-53$

Klein, R.T.J.; Eriksen, S.E.H.; Næss, L.O.; Hammill, A.; Tanner, T.; Robledo, C. and O'Brien, K.L. (2007) Portfolio Screening to Support the Mainstreaming of Adaptation to Climate Change into Development Assistance, Tyndall Centre Working Paper 102, Norwich: Tyndall Centre

Lahsen, M. (2007) 'Trust Through Participation?

Problems of Knowledge in Climate Decision 
Making', in M. Pettinger (ed.), The Social Construction of Climate Change, Aldershot: Ashgate: 173-96

Lievrouw, L. A. and Farb, S.E. (2003) 'Information and Equity', Annual Review of Information Science and Technology 37: 499-540

Lunch, N. and Lunch, C. (2006) Insights into Participatory Video: A Handbook for the Field, Oxford: Insight

Martin, M.; Brookes, L.; Cham, A.; Sowe, D.M.; Khan, S.; Thomas, D.R. and Hill, P.C. (2005) 'Tuberculosis Education in an Endemic Setting: Application of Participatory Methods to Video Development in The Gambia', International Journal of Tuberculosis and Lung Disease 9.5: 550-5

Mendler, J.; Simon D. and Broome, P. (2002) 'Virtual Development and Virtual Geographies: Using the Internet to Teach Interactive Distance Courses in the Global South', Journal of Geography in Higher Education 26.3: 313-25

Mitchell, T. and Tanner, T.M. (2006) Adapting to Climate Change: Challenges and Opportunities for the Development Community, Middlesex: Tearfund

Mitchell, K.; Nakamanya, S.; Kamali, $A$. and Whitworth, J.A.G. (2001) 'Community-based HIV/AIDS Education in Rural Uganda: Which Channel is Most Effective?', Health Education Research 16.4: 411-23

O'Brien, G.; O'Keefe, P.; Rose, J. and Wisner, B. (2006) 'Climate Change and Disaster Management', Disasters 30.1: 64-80

Patt, A.G. and Gwata, C. (2002) 'Effective Seasonal Climate Forecast Applications: Examining Constraints for Subsistence Farmers in Zimbabue', Global Environmental Change-Human and Policy Dimensions 12.3: 185-95

Patt, A.G.; Dazé, A. and Suarez, P. (2008, in press) 'Gender and Climate Change Vulnerability: What's the Problem, What's the Solution?', in M. Ruth and M.E. Ibarraran (eds), Distributional Impacts of Climate Change and Disasters: Concepts and Cases, Cheltenham: Edward Elgar

Patt, A.G.; Suarez, P. and Gwata, C. (2005) 'Effects of Seasonal Climate Forecasts and Participatory Workshops Among Subsistence Farmers in Zimbabue', Proceedings of the National Academy of Sciences 102.35: 12623-8

Pearce, L. (2003) 'Disaster Management and Community Planning, and Public Participation: How to Achieve Sustainable Hazard Mitigation', Natural Hazards 28.2-3: 211-28

Pink, S. (2004) 'Participatory Video: Images that Transform and Empower', European Journal of Communication 19.3: 411-2
Rimm, M. (2003) 'Extension Materials for Meatborne Parasitic Diseases in Developing Countries', Acta Tropica 87.1: 171-5

Roncoli, C. (2006) 'Ethnographic and Participatory Approaches to Research on Farmers' Responses to Climate Predictions', Climate Research 33: 81-99

Suarez, P. and Mendler de Suarez, J. (2006) Videomediated Approaches for Community-level Adaptation, report to the Potsdam Institute for Climate Impact Research for the project 'Use of Video Tools for Disaster Management and Climate Adaptation', Potsdam, Germany: Potsdam Institute

Tanner, T. and Mitchell, T. (2008) Entrenchment or Enhancement: Could Climate Change Adaptation Help Reduce Chronic Poverty?, Working Paper 106, Manchester: Chronic Poverty Research Centre

Thomalla, Fi; Downing, T.; Spanger-Siegfried, E.; Han, G. and Rockström, J. (2006) 'Reducing Hazard Vulnerability: Towards a Common Approach between Disaster Risk Reduction and Climate Adaptation', Disasters 30.1: 39-48

UNDP (United Nations Development Programme) (2003) Poverty and Climate Change: Reducing the Vulnerability of the Poor through Adaptation, London: Department for International Development

van Aalst, M.K.; Cannon, T. and Burton, I. (2008) 'Community Level Adaptation to Climate Change: The Potential Role of Participatory Community Risk Assessment', Global Environmental Change 18: 165-79

Whitehead, D. (2000) 'Using Mass Media within Health-promoting Practice: A Nursing Perspective', Journal of Advanced Nursing 32.4: 807-16

Wisner, B. and Uitto, J. (2008) 'Life on the Edge: Urban Social Vulnerability and Decentralized, Citizen-Based Disaster Risk Reduction in Four Large Cities of the Pacific Rim', in H.-G. Brauch et al. (ed.), Globalization and Environmental Challenges: Reconceptualizing Security in the 21st Century, Hexagon Series on Human and Environmental Security and Peace, Vol. 3, Berlin: Springer-Verlag

Wisner, B.; Blaikie, P.; Cannon, T. and Davis, I. (2004) At Risk: Natural Hazards, People's Vulnerability and Disasters, 2nd edn, London: Routledge

Ziervogel, G. and Downing, T.E. (2004) 'Stakeholder Networks: Improving Seasonal Forecasts', Climatic Change 65: 73-101 